\title{
Study on the Prevalence of Ovine Fasciolosis in Wadla Woreda, North Wollo, Ethiopia
}

\author{
Chekol B ${ }^{1}$ and Girma $\mathrm{Y}^{2 *}$ \\ ${ }^{1}$ College of Agriculture, Department of Animal Health, Wollo University, Ethiopia \\ 2Ministry of Livestock and Fisheries, Addis Ababa, Ethiopia
}

*Correspondent author: Yeshibely Girma, Ministry of Livestock and Fisheries, Addis Ababa, Ethiopia, Email: girmayeshibelay@gmail.com

\section{Research Article}

Volume 3 Issue 1

Received Date: February 08, 2018

Published Date: March 29, 2018

\section{Abstract}

A cross-sectional study on the prevalence of ovine fasciolosis was conducted in Wadla district from October 2016 to June 2017. A total of 384 fecal samples were randomly collected directly from the rectum of individual animals. Parasitological investigation was performed using sedimentation technique. From a total of 384 copro-logically examined samples 130 sheep were found positive for fasciolosis with an overall prevalence of $33.85 \%$. From the study peasant association Kone, Dorera, Betehar, Beteyohannis and Gashena were accounted for 34.61\%, 32.47\%, 32.89\%, 35.06\% and $34.21 \%$ respectively. The difference in the prevalence in the five peasant associations was not statistically significant ( $p>0.05)$. The prevalence of ovine fasciolosis was computed for the different age, sex and body condition categories. The prevalence rate of fasciolosis in young sheep $32.43 \%$ was less than $34.75 \%$ and the difference were not statistically significant ( $p>0.05$ ). The prevalence of fasciolosis in sex groups in the present study was $34.69 \%, 32.98 \%$ in female and male respectively. On the other hand in the present study area the prevalence of fasciolosis was found to be higher in sheep with poor body condition than those with medium and good body conditions with prevalence of $36.5 \%$, 33.88\% and $27.03 \%$ respectively. There is no statistically difference ( $p>0.05$ ) between three types of body condition scores. It was concluded that ovine fasciolosis was prevalent, thus causing major economic lass in the study area. Hence, control strategies targeted on the parasite and the intermediate hosts as well as implementation of appropriate grazing management in the study area are warranted.

Keywords: Fasciolosis; Prevalence; Ovine; Wadla Woreda

\section{Introduction}

Ethiopia has an enormous livestock resource with a total contribution of $15 \%$ gross domestic product and
$33 \%$ agricultural output [1]. Ethiopia hosts large number of small ruminants that are raised under external pastoral production system or in adjunct to crop production. The estimated small ruminant population of Ethiopia is about 26.2 million sheep and 21.7 million goats [2]. 
However this huge potential of wealth is untapped to the livelihood of village farmers and the contribution to national economy at large is minimal the reason being predominance of infection and parasitic disease, age-old traditional management system, lack of genetic selection for good performance coupled with under and malnutrition and parasitic diseases are common traits that affect productivity. Among the many parasitic problems of the domestic animals fasciolosis is a major disease which imposes direct and indirect economic impact on livestock production in ruminants [3].

Fasciola species is the most important trematode of domestic ruminants. Fasciolosis is the commonest of liver fluke disease in the temperature of the world. The complete life cycle of fasciola is realized by the presence of suitable intermediate host for the development of miracidium through metacercariae which is an infective stage for the final host. There are three main factors influencing the production of the large numbers of metacercariae necessary for outbreaks of fasciolosis. Those factors are availability of snail habitat (i.e., lymnaeatruncatula prefers mud to free water) temperature $\left(10^{\circ} \mathrm{C}\right.$ and above $)$ and moisture for the breeding of snail and for the development of fasciola $[4,5]$.

Fasciolosis can be caused by the F. hepatica, which is widely distributed in temperate and cooler areas of high altitude in tropics and subtropics area and F. gigantic which is widely distributed in tropical areas. Fasciolosis (caused by F. hepatical and F. gigantic) is one of the most prevalent helminthes infections of ruminants in different parts of the world. It causes significant morbidity and mortality [6].

Since fasciolosis is major parasitic disease of small ruminants an estimate of economic loss due to ovine fasciolosis in the Ethiopia highlands was made based on available data on mortality, weight loss reduced reproduction efficiency and liver condemnation at slaughter. The economic effects of fasciolosis where identified and models for estimating the financial loss presented. Ovine fasciolosis losses were estimated at 48.4 mills. Birr per/yr of which $46.5 \%, 48.8 \%$ and $4.7 \%$ were due to mortality, productivity or weight loss and reproductive wastage and liver condemnation respectively. These losses can be reduced substantially by fasciolosis control programs that may be including the use of antihelmentics, grazing management and nutritional supplementation $[7,8]$.

A high prevalence of fasciolosis was reported in different parts of the country by different researchers including Molalegn, et al., Basaznew, et al., Eyerusalem, et al., Tesfaheywet and Negash, Eyob, et al., [9-13]. Despite the significance of this parasitic infection, there is no documented report on the occurrence of ovine fasciolosis in the present study area, where small ruminants are important assets to the community. Therefore, the objective of the study was to determine the prevalence of ovine fasciolosis in the Wadla woreda and identify the major risk factors of the disease.

\section{Materials and Methods}

\section{Study Area}

The study was conducted in Wadla District (Woreda), North Wollo zonal administration in the Amhara Regional state of Ethiopia. This area has mid- sub tropical weather "weyna dega", high land temperature type "Dega" and low land temperature type "Kola" accounting 23\%, 75\% and $2 \%$ of the climate respectively. The woreda is situated at $642 \mathrm{~km}$ north of Addis Abeba, the capital city of Ethiopia. The mean annual temperature and rain fall ranges between 8 to $20{ }^{\circ} \mathrm{C}$ and 850 to $1050 \mathrm{~mm}$. The altitude ranges from 2780 to 3200 meters above sea level.

The livestock population of the district is estimated at 57, 386 cattle, 160,023 sheep's, 11,195 goats, 4,276 and 14,820 equine [14].

\section{Study Animals}

A total of 384 sheep from the woreda were subjected to qualitative coproscopic examination to determine the overall prevalence rates in the study area. All examined animals were local breeds of mixed age, sex groups and different body conditions.

\section{Study Design}

A cross sectional study method was conducted by selecting animals randomly to determine the prevalence of ovine fasciolosis in the woreda.

\section{Sampling Method and Sample Sizes}

Simple random sampling method was applied to take the samples and the sample frame was peasant association (pas) found within wadla woreda. Five pas were randomly selected from 15 pas presented in the woreda. From the selected 5 peasant association the sample size was calculated by using $50 \%$ expected prevalence to get the sample size, because there were no previous prevalence studies in the woreda. Using Thrusfield [15] formula: accordingly, the minimum sample size needed is 384 . 


$$
n=\frac{(1.96)^{2} P_{e x p}\left(1-P_{e x p}\right)}{d^{2}}
$$

Where; $n=$ sample size; $P_{\text {exp }}=$ expected prevalence; $d^{2}=$ desired absolute precision of $95 \%$ confidence interval.

\section{Coproscopy}

Faecal sample were collected directly from the rectum of each sheep species put in universal bottles and preserved with $5 \%$ formalin's, and then it was taken to laboratory and examined. There was same laboratory techniques employed, that are direct faecal smear and sedimentation for the detections of fasciola eggs.

\section{Determination of Age and Body Condition Scores}

Since most small ruminant holder farmers do not usually keep records; it was difficult to obtain information on the age of animals from the owner. Hence age of every sampled sheep was determined based on dentition as indicated by Vatta, et al. [16] and conveniently categorized as young and adults. Body condition score of each animal was determined based on criteria set by Thompson and Meryer, [17] using the 5 point scale (1=very thin to $5=$ obeys). It can be assessed by palpation around the lumbar vertebrae between the back of the ribs and the front of the pelvic bones. However; for in this study, the animals were categorized in poor, medium and good body condition.

\section{Data Analysis}

Data collected from laboratory result was stored on Microsoft (ms) excel spread sheet program, and analysis was done by using SPSS version 20 software program. Categorical variables (sex, age, area and body conditions scores) were expressed in percent. Prevalence was defined as the proportion of the animals (sheep) positive for fasciolosis by coprological examination to the total of animals examined, which was expressed in percent. The association between each risk factors and the outcome variable was assessed using $\left(\chi^{2}\right)$ test. For all analysis, a pvalue of less than 0.05 was taken as significant.

\section{Results}

From the total of 384 examined sheep fecal samples, $130(33.85 \%)$ samples were positive for fasciolosis, the prevalence of ovine fasciolosis in the five peasant associations ( pas) were 34.61\%, 32.47\%, 32.89\%, $35.06 \%$ and $34.21 \%$ in Kone, Dorera, Betehor, Beteyohannis, Gashena respectively. The prevalence of fasciolosis between the study sites showed statistically not significant difference $\left(\chi^{2}=0.1723, P>0.05\right)$ (Table 1$)$.

\begin{tabular}{|c|c|c|c|}
\hline Pas & $\begin{array}{c}\text { No. of animal } \\
\text { examined }\end{array}$ & $\begin{array}{c}\text { No. of } \\
\text { positive }\end{array}$ & $\begin{array}{c}\text { Prevalence } \\
\text { (\%) }\end{array}$ \\
\hline Kone & 78 & 27 & 34.61 \\
\hline Dorera & 77 & 25 & 32.47 \\
\hline Betehor & 76 & 25 & 32.89 \\
\hline Beteyohannis & 77 & 27 & 35.06 \\
\hline Gashena & 76 & 26 & 34.21 \\
\hline Total & 384 & 130 & 33.85 \\
\hline
\end{tabular}

Table 1: The Prevalence of ovine fasciolosis in different Pas.

$\chi^{2}=0.1723 . \operatorname{Pr}=0.996497, p>.05$ (statistically not significant), pas $=$ peasant association

Infection rates between male and female animals were compared. Statistical analysis showed not significant difference ( $\mathrm{P}>0.05$ ) that is $34.69 \%$ in female and $34.98 \%$ in males (Table 2).

\begin{tabular}{|c|c|c|c|}
\hline Sex & $\begin{array}{c}\text { No. of animal } \\
\text { examined }\end{array}$ & $\begin{array}{c}\text { No. of } \\
\text { positive }\end{array}$ & Prevalence (\%) \\
\hline Female & 196 & 68 & 34.69 \\
\hline Male & 188 & 62 & 34.98 \\
\hline Total & 384 & 130 & 33.85 \\
\hline
\end{tabular}

Table 2: The Prevalence of ovine fasciolosis on sex basis. $\chi^{2}=0.1261, p r=0.722554, p>.05$ (statistically not significant).

Analysis of the prevalence rates on age basis showed no significant difference ( $\mathrm{P}>0.05), 189(32.43 \%)$ were young animals (<below 2 yrs old) and 236 (34.75\%) adult animals (above 2 yrs old) (Table 3 ).

\begin{tabular}{|c|c|c|c|}
\hline Age groups & $\begin{array}{c}\text { No. of animal } \\
\text { examined }\end{array}$ & $\begin{array}{c}\text { No. of } \\
\text { positive }\end{array}$ & $\begin{array}{c}\text { Prevalence } \\
\text { (\%) }\end{array}$ \\
\hline Young $(<2$ Yr $)$ & 148 & 48 & 32.43 \\
\hline Adult $(>2$ Yr $)$ & 236 & 82 & 34.75 \\
\hline Total & 384 & 130 & 33.85 \\
\hline
\end{tabular}

Table 3: Prevalence of ovine fasciolosis on the age bases. $\chi^{2}=0.2174, \operatorname{Pr}=0.64105, \mathrm{p}>.05$ (statistically not significant)

On the present study area prevalence of Fasciolosis were found to be higher in sheep with poor body condition than those with medium and good body conditions, with the prevalence of $36.5 \%, 33.88 \%$ and $27.03 \%$ respectively (Table 4 ). 


\begin{tabular}{|c|c|c|c|}
\hline $\begin{array}{c}\text { Body } \\
\text { condition } \\
\text { score }\end{array}$ & $\begin{array}{c}\text { Number of } \\
\text { examined }\end{array}$ & $\begin{array}{c}\text { Number of } \\
\text { positive }\end{array}$ & $\begin{array}{c}\text { Prevalence } \\
\text { (\%) }\end{array}$ \\
\hline Poor & 189 & 69 & 36.5 \\
\hline Medium & 121 & 41 & 33.88 \\
\hline Good & 74 & 20 & 27.03 \\
\hline Total & 384 & 130 & 33.85 \\
\hline
\end{tabular}

Table 4: The Prevalence of ovine fasciolosis on the bases of body condition score.

$\chi^{2}=2.1347, \operatorname{Pr}=0.343918, \mathrm{p}>.05$ (statistically not significant).

\section{Discussion}

Fasciolosis is a prevailing ruminant health quandary and causes substantial economic losses to the livestock commerce in Ethiopia. The overall prevalence of ovine fasciolosis by coprological examinations in the present study area was $33.85 \%$. The present finding was relatively agreed with previous works reported prevalence $32.7 \%, 30.7 \%, 36.2 \%, 35.94 \%$ and $35.68 \%$ by Dinka (1996) [18] in Assella, Megerssa, et al. (2017) [19] in Sherka woreda Arsi, Kasanesh, et al. (2017) [20] in Gondar, Eyob, et al. (2014) [13] in North shoa and Melkamu and Mulat (2015) [21] in South Wollo respectively. This similarity might be similar agro-ecology with the present study areas.

The present finding was relatively higher than Mathewos, et al. (2014) [22] in Alamata, Ethiopia, Ahmed, et al. [8] in Middle Awash Basin, Musa (2009) [23] in around Bahir-Dar and Henok and Mekonnen [24] in Hirna town with the prevalence of $24.2 \%, 13.2 \%, 15.8 \%$ and $14.6 \%$ respectively. This difference might be due to agro ecological different, the availability of suitable or favorable intermediate snail habitat in the area.

However, the present study was relatively lower than the other reports in different parts of Ethiopia like Asrede and Shifaw [25] in Debre Birhan, Molalegn, et al. [9] in Dawa Cheffa, Kemissie and Basaznew, et al. [10] in Yilmana Densa District West Gojjam with the prevalence of $50.8 \%, 49 \%$ and $42.44 \%$ respectively. This variation might be in different geographical location or management system variation of the smallholder farmers or lack of awareness about seasonal deworming of small ruminants in these areas. Climatic variations are of supreme importance influencing factors for the epidemiology of fasciolosis [26].

The prevalence of fasciolosis in male and female animals was recorded as $34.98 \%$ and $34.69 \%$ respectively. The results showed that coprological prevalence of ovine fasciolosis was similar in female and male animals in the study areas. According to Solomon [27] reports both sexes have been equally affected with fasciolosis and a higher prevalence of parasitic infection was not associated with sex $(p>0.05)$. The fact that prevalence of fasciolosis between male and female are not significantly difference, sex of sheep has not impact on the prevalence of fasciolosis. They exposed to graze and parasitic infection with equal rate. Sex did not show significant variation on the prevalence of Fasciola, similar finding was shown by Demil, et al. [28]. This might also be due to grazing of both sex groups in similar Fasciola contaminated pasture land.

The prevalence between different age groups of animals were found to be statistically not significant $(p=0.641)$. This might be due to grazing of young animals with the adults early after some days of parturition. The somewhat higher prevalence was recorded in the adults and relatively lowers in the young animals. This might be young animals are not usually allowed to go far with adults for grazing. So the chance of exposure to infective metacercaria was lower as compared with adult animals. Similar results were reported by Chanie [29] and Ibrahim, et al. [30]. In the present study result indicated that relatively higher infection rate of fasciolosis were observed in sheep with poor body condition than medium and good body conditions. So it indicates that fasciolosis disease causes reducing of body weight gains.

\section{Conclusions and Recommendations}

Fasciolosis is a major obstacle for sheep production and productivity by inflicting remarkable direct and indirect losses at different parts of the country. The study has investigated the prevalence of ovine fasciolosis in reared sheep under extensive farming system in Wadla district of the Amhara regional state, western Ethiopia. The result of the present study indicated that fasciolosis is a higher prevalent sheep disease in the study area. This parasitic disease is distributed in every corner of the country, even the rate is different and considered as one of the major setbacks to sheep product utilization causing direct and indirect losses. The findings of the current study revealed that fasciolosis is still a health problem in the study area. Presence of favorable conditions like swampy area, stagnant water bodies, scarcity of feed, poor management practices and other concurrent diseases can facilitate the infectivity of the parasite in the area. The present study suggest that furthers strategic control of snails is required in order to overcome the problems of ovine fasciolosis at the study area. 


\section{Open Access Journal of Veterinary Science \& Research}

Therefore based on the above conclusion the following recommendations are forwarded:

$>$ A further study using alternative techniques such as serology in combination with fecal test surveys need to be conducted in different seasons in order to generate more complete data on the prevalence of ovine fasciolosis.

> Appropriate strategic deworming has to be designed and implemented in the study area to minimize the effect of the disease on livestock productivity.

> Strategic intermediate host the snail control through different techniques should be undertaken.

> Policy makers and economy analysts have to be provoked to put their relentless effort in the control of the disease that has serious impact on the country economy.

\section{Acknowledgment}

We would like to thank Wollo University, College of Veterinary Medicine staff members for their cooperation and supports.

\section{Conflicts of Interest}

We declare that there is no any conflict of interest.

\section{References}

1. DACA (Drug administration and controlling authority) (2006) Guideline for the Regulation of Promotion and Advertisement of Drugs, 2 ${ }^{\text {nd }}$ (Edn.), Addis Ababa, Ethiopia, pp: 29-35.

2. CSA (Central statistical agency) (2009) Agricultural survey report on livestock, poultry and bee hives population, private peasant holdings. Addis Ababa, Ethiopia, pp: 2.

3. Shanko K, Olgira W (2016) The Prevalence Study of Ovine Fasciolosis in Jima Rare District, Horo Guduru Wollega Zone, Oromia Regional State, Western Ethiopia. J Veterinar Sci Technol 7(1): 277.

4. Urquhart GM, Armour J, Duncan JL, Dunn AM, Jennings FW (1996) Veterinary Parasitology. 2nd edn., Oxford, UK. Longman Scientific and Technical Press, pp: 100-109.

5. Hutchinson G, Stephen L (2007) Liver fluke disease in sheep and cattle: prime fact 446: 2 .

6. Okewol EA, Ogundipe GAT, Adejinmi JO, Olaniyan AO (2000) Clinical evaluation of three chemoprophylactic regimes against ovine helminthosis in a Fasciola endemic farm in Ibadan, Nigeria. Israel J Vet Med 56: 15-28.

7. Anderson N, Luong TT, Bui KL, Smoker PM, Spithill TW (1999) The sensitivity and specificity of two methods for detection Fasiola in catele. Journal of veterinary parasitology $83: 15-24$.

8. Ahmed EF, Markvichitr K, Tumwasorn S, Koonawootrittriron S, Choothesa A (2007) Prevalence of fasciola species infections of sheep in the middle awash river basin, Ethiopia. South East Asian J Trop Med Public Health 38: 51-57.

9. Molalegn B, Nuradis I, Nahili A (2010) Study on the prevalence of ovine, fasciolosis in around Dawa Cheffa, Kemissie, Ethiopia. African Journal of Agriculture Reaserch 5(21): 2981-2985.

10. Basaznew BM, Abeje, Mersha C (2012) Pervasiveness of Fasciolosis in Sheep in YilmanaDensa District, West Gojjam Zone, Amhara Region, North western Ethiopia. Acta Parasitological Globalist 3(3): 34-37.

11. Eyerusalem G, Yeshitila A, Mihreteab B (2012) Prevalence of Ovine Fasciolosis in Adigrat, North East Ethiopia, Global Veterinaria 9(1): 92-96

12. Tesfaheywet $Z$, Negash K (2012) Prevalence of Ovine Fasciolosis in Oda Bultum Woreda, Western Hararghe, Ethiopia. Global Veterinaria 9 (5): 530-534.

13. Eyob H, Faye G, Morka A, Dabela A (2014) Ovine Fasciolosis Prevalence in Hidebu Abote Woreda, North Shoa, Ethiopia. American-Eurasian Journal of Scientific Research 9(4): 82-86.

14. Wadla woreda Livestock office data (2016) Annual report of Wadla woreda animal population data.

15. Thrusfield M (2007). Veterinary Epidemiology. 3rd edn. Blackwell Science Ltd., London, UK, pp: 228-246.

16. Vatta AF, Abbot MA, Villiers JF, Gumede SA, Harrison LJS, et al. (1988) Seasonal prevalence of protostrongylid and Dictyocaulus Species of lungworms in Awassi sheep in North-West Syria. Trop Anim Heal Prod 20: 187-189.

17. Thompson JM, Meyer H (1994) Body condition scoring of sheep. Department of Animal Sciences, Oregon State Universty. pp: 1-6. 


\section{Open Access Journal of Veterinary Science \& Research}

18. Dinka A (1996) Preliminary study on prevalence of fasciolosis in small ruminants in and around Assela (Arsi). DVM Thesis, Faculty of Veterinary Medicine, Addis Ababa University, Debrezeit, Ethiopia.

19. Megerssa YC, Jima TB, Diriba YM, W/Mariyam FT (2017) Burden of Ovine Fasiolosis in Sherka Woreda Arsi, Ethiopia. J Vet Sci Technol 8(2): 426.

20. Kasanesh Destaw, Wakuma Mitku, Muhammed Hamid, Bethelehem Alemu, Tarekegn Tintagu (2017) Prevalence of ovine fasciolosis in selected Kebeles of Wogera District, North Gondar zone, Ethiopia. Int J Adv Res Biol Sci 4(8): 78-84.

21. Melkamu S, Mulat A (2015) Study on the Prevalence of Ovine Fasciolosis in Ambasel Woreda, South Wollo Zone, Amhara Regional State, Ethiopia. J Ani Res 5(3): 437-441.

22. Mathewos T, Tadesse D, Zawdneh T (2014) Prevalence and Associated Risk Factors for Ovine Fasciolosis in Selected Sub-Districts of Alamata District, Ethiopia Global Veterinaria 13(5): 738-744.

23. Musa Y (2009) Studies on the prevalence of ovine fasciolias in and around Bahir Dar, DVM thesis, Gondar University, Gondar, Ethiopia.

24. Henok M, Mekonnen A (2011) Study on prevalence and risk factors of fasciolosis in small ruminants in and around Hirna Town, Ethiopia. Global Veterinaria 7: 497-501.
25. Asrede T, Shifaw A (2015) Coprological Study on the Prevalence of Ovine Fasciolosis in Debre Birhan Agricultural Research Center, Ethiopia. European Journal of Biol Sci 7(3): 103-107.

26. Ansari-lari M, Moazzen M (2006) A retro-spective survey of liver fluke disease in livestock based on abattoir data in Shiraz, south of Iran. Prev Vet Med 73(1): 93-96.

27. Solomon W (2005) Effect of strategic anthelmintic treatment on ruminant fasciolosis in Upper Blue Nile Basin, North Western Ethiopia, Addis Ababa University, Msc. thesis, pp: 78.

28. Demil E, Mekonnen A, Adugna T, Assefa W, Bialfew T (2017) Prevalence of Ovine Fasciolosis in and around Motta Town, North-West Ethiopia. Europ J Biol Sci 9(2): 79-84.

29. Chanie M, Begashaw S (2012) Assesment of the economic impact and prevalence of ovine fascilosis in Menz Lalo Midir District, North Shoa, Ethiopia. Vet World 5(5): 261-264.

30. Ibrahim A, Nölkes D, Gezahegn E, Taye M (2017) Prevalence of Ovine Fasiolosis in Jimma and Selected Rural Kebeles Near Jimma, Southwest Ethiopia. J Vet Sci Technol 8: 424. 